\title{
European Put-Call Parity and the Early Exercise Premium for American Currency Options
}

\author{
Geoffrey Poitras \\ Simon Fraser University, Canada \\ Chris Veld \\ University of Stirling, U.K. \\ Yuriy Zabolotnyuk* \\ Carleton University, Canada
}

\begin{abstract}
The European put-call parity condition is used to estimate the early exercise premium for American currency options traded on the Philadelphia Stock Exchange. Using a sample of 331 pairs of call and put options with the same exercise price and time to expiration, evidence is provided for early exercise premiums that average $5.03 \%$ for put options and $4.60 \%$ for call options. The premiums for both call and put options are strongly related to the interest rate differential and time to expiration. These results have implications for the use of European option pricing models in the valuation of American options. (JEL: G10, G12, G13, G14)
\end{abstract}

Keywords: European put-call parity; currency options; early exercise premium

\section{Introduction}

Most exchange traded options are American style and can be exercised at any time up to the expiration date. This causes a problem because the

\footnotetext{
* Geoffrey Poitras is Professor of Finance in the Faculty of Business Administration, Simon Fraser University, Vancouver, Canada. Chris Veld is Professor of Finance in the Division of Accounting and Finance, Stirling Management School, University of Stirling, U.K. Yuriy Zabolotnyuk is Assistant Professor of Finance at the Sprott School of Business, Carleton University, Ottawa, Canada. The authors thank Hon-Lu Chun, Robbie Jones, Frans de Roon, Peter Spencer, Yulia Veld-Merkoulova and participants in the Multinational Finance Society Conference in Edinburgh (June 2006) for helpful comments and suggestions. Bertha Wong and Yvonne Yip provided research assistance. Financial is also support from the acknowledged Social Sciences and Humanities Research Council of Canada.
}

(Multinational Finance Journal, 2009, vol. 13, no. 1/2, pp. 39-54)

(C) Multinational Finance Society, a nonprofit corporation. All rights reserved.

DOI: $10.17578 / 13-1 / 2-2$ 
benchmark formula for the valuation of currency options - the Garman-Kohlhagen (GK) currency option variant of the Black-Scholes model - does not take the premium for early exercise into account. ${ }^{1}$ In order to apply the GK model to traded options, information on the size of the early exercise premium and the factors that determine this premium are important, if only for interpreting the behavior of the implied volatilities that are estimated from traded options. In this paper, a methodology developed by Zivney (1991) and de Roon and Veld (1996) for estimating the early exercise premium is applied to currency options. Unlike equity options where early exercise behavior occurs only for short dated options with dividend payments close to the expiration date, currency options are a prime candidate for early exercise. ${ }^{2}$ When deep in the money, call options on high-interest currencies and put options on low-interest currencies are likely to be exercised early. The empirical results examine 331 pairs of call and put currency options traded on the Philadelphia Stock Exchange between 2/1/1992 and 24/9/1997. Over the admissible range of exercise pairs considered, the average early exercise premium is $5.03 \%$ for put options and $4.60 \%$ for call options. The premiums are strongly related to the interest rate differential and, to a lesser extent, time to expiration.

\section{The Early Exercise Decision}

Despite being essential to the valuation of American options, the trading fundamentals of the early exercise decision have not received much attention. An understanding of the optimal solutions for the relevant market participants is needed to explain the behavior of the early exercise premium. Two general decision problems are encountered: maximizing the discounted expected value for the option holder; and maximizing arbitrage profit for a market maker. The solution of the arbitrage for the market maker determines the prices which are used in the option holder decision problem. In many cases, as the American option goes deep in the money the market maker will only be willing to quote the intrinsic value (time value equals zero) providing no incentive for the holder to sell the option in the market instead of exercising

1. On the Garman-Kohlhagen model, see Garman and Kohlhagen (1983). Bollen and Rasiel (2003) provides a recent discussion of this and other currency option models.

2. See e.g. Bodurtha and Courtadon (1995). 
early. ${ }^{3}$ When the discounted expected value of holding the option to maturity is less than that for exercising the option and holding the underlying security obtained until the expiration date, early exercise is triggered. For call options on stocks paying dividends at discrete intervals, this typically occurs for dividend payment dates close to the expiration date. For options on currencies, the difference between the foreign and domestic interest rates drives the early exercise decision.

Two necessary conditions for the occurrence of an early exercise event are that: there be a traded American option to exercise; and, the option being exercised is in the money. In practical terms, this means that options for exercise were created at a prior time when the relation between spot price, exercise price and time to expiration required a non-trivial time value in the option price. Because option exercise involves a surrender of the time value that could be obtained if the option is sold instead of exercised, at the time of an exercise event, the prices quoted by the market maker are effectively equal to the intrinsic value, having little or no time value. To see this, consider the market maker's (bid) quote at time $t$ for a deep in the money call option on a non-dividend paying stock, e.g., Poitras (2002, p.378-381). In order to hedge this purchase at price $C(t)$, the market maker would short the stock at $s(t)$ and invest the balance in a riskless bond maturing on the expiration date. If the deep in the money option is quoted at intrinsic value $(s(t)-X)$ - stock price minus exercise price - then after purchasing the call option and shorting the stock the market maker would be able to invest $X$ in the riskless bond at interest rate $r$. Assuming perfect markets, this would generate a profit $(\pi)$ on the expiration date $(T)$ of:

$$
\pi_{m}(T)=X e^{r(T-t)}+\max [0, s(T)-X]-s(T)
$$

Because this represents a profit in all future states of the world, it follows that the market maker would quote a higher price than the intrinsic value and the call option would be sold by the holder and not exercised. This is the basis for the well known result that the early exercise premium for an American call option on a non-dividend paying stock is zero because the probability of early exercise is zero.

For an option on a stock with discrete dividend payments, the short

3. Intrinsic value is defined as the maximum of zero or the current spot price minus the exercise price for a call, and conversely for a put. The time value is the current option price minus the intrinsic value. 
stock position will also be responsible for any dividends paid between the trade date and the expiration date. Taking $D$ to be the future value of the dividend payment at $T$, the profit for the market maker is now:

$$
\pi_{m}(T)=X e^{r(T-t)}+\max [0, s(T)-X]-(s(T)+D)
$$

For dividend payment dates close to the expiration date, this profit can be negative and there is no incentive to quote prices above intrinsic value. In this case, the option holder will receive $\max [0, s(T)-X]$ if the option is held to maturity. If the option is exercised early, an instant before the ex dividend date, the holder will borrow $X$ and use the funds to purchase the stock. At expiration the profit will be:

$$
\pi_{h}(T)=(s(T)+D)-X e^{r(T-t)}
$$

Assuming the option is far enough in the money and the time to expiration is short enough that the probability of $s(T)<X$ is zero, then early exercise will be more profitable than holding the call option to maturity if the value of the dividend received exceeds the interest cost of the funds borrowed to exercise the option.

The early exercise decision for currency options differs substantively from equity options. In particular, let $S(t)$ be the exchange rate measuring the value of 1 unit of foreign currency in terms of a reference (domestic) currency. As such, a call option giving the right to purchase 1 unit of foreign currency in exchange for a stated amount of the reference currency is identical to a put option giving the right to sell the stated amount of reference currency in exchange for 1 unit of foreign currency. If the call option is quoted at intrinsic value at time $t$, then the market maker can borrow 1 unit of foreign currency at foreign interest rate $r^{*}$, convert at $S(t)$ to buy the call option for $S(t)-X$ and invest the remaining funds at the domestic interest rate $r$ in a riskless bond. The market maker's profit at $T$ would be:

$$
\pi_{m}(T)=X e^{r(T-t)}+\max [0, S(T)-X]-\left(S(T) e^{r *(T-t)}\right)
$$

Similarly, the market maker profit for a put option would involve borrowing $X$ in the domestic market, buying the put option at intrinsic value $X-S(t)$ and converting the balance of funds to foreign currency, investing at the foreign interest rate and converting the proceeds back to the reference currency at $S(T)$. The profit in this case is: 


$$
\pi_{m}(T)=\left(S(T) e^{r *(T-t)}\right)+\max [0, X-S(T)]-X e^{r(T-t)}
$$

It follows that, as the call or put gets deep in the money, the incentive for the market maker to quote prices above intrinsic value depends on $\left(r-r^{*}\right)$.

Faced with quoted prices at intrinsic value, the deep in the money call option holder at time $t$ will borrow $X$ at interest rate $r$, exercise the option by paying $X$ to receive $S(t)$, converting to 1 unit of foreign currency, investing at $r^{*}$ and converting the proceeds back to the reference currency at $S(T)$. At time $T$, the profit would be:

$$
\pi_{h}(T)=\left(s(T) e^{r *(T-t)}\right)-X e^{r(T-t)}
$$

Assuming the call option is deep enough in the money that the probability of $S(T)<X$ is zero, early exercise will be triggered whenever this value exceeds the profit from holding the option till maturity ( $\max$ $[0, S(T)-X]$ ), i.e., when $r^{*}>r$. Similarly, early exercise for the put option will be triggered when $r>r^{*}$. Unlike equity options, where early exercise is triggered by discrete dividend payments close to the expiration date, currency options depend on the difference between $r^{*}$ and $r$, and how deep in the money the option is. Early exercise can occur for relatively long-dated currency options, if the option is deep enough in the money that the probability of the option finishing out of the money is negligible. Because of the lack of incentives for the market maker to quote prices above intrinsic value for deep in the money options, early exercise has additional value for option holders seeking to sell the position prior to maturity.

\section{Methodology}

Zivney (1991) provides a methodology to derive the early exercise premium for American options on an equity index using the European put-call parity condition. This is of practical importance because exchange traded options are usually American, while closed form pricing formulas are only available for European options. ${ }^{4}$ Recognizing the difficulties associated with discrete dividend payments of the equity index used by Zivney (1991), De Roon and Veld (1996) refine this methodology for an index in which dividends are automatically

4. Laprise, et al. (2006) is a recent review of the complications and difficulties of determining a pricing formula for American options. 
reinvested. Other sources, such as Dueker and Miller (2003), Poitras (2002,p.396-397) and Engström and Nordèn (2000), also examine the implications for equity options. ${ }^{5}$ As discussed above, this focus on equity options in previous studies is significant due to differences in the early exercise decision for currency options. In general, the incentives to exercise currency options early are significantly greater than for equity options. In addition, the net interest gains from early exercise for currency options will typically be larger than comparable gains for equity options, due to the relatively smaller size of dividend payments compared to interest payments.

Adapting the Zivney (1991) methodology to currency options, deviations from European put-call parity are used to measure the early exercise premium for American currency options. Using continuous compounding, European put-call parity has the following form:

$$
c(t)-p(t)=S(t) e^{-r *(T-t)}-X e^{-r(T-t)}
$$

where $c(t)$ and $p(t)$ are the European call and put prices,both unobserved at $t$. Using (1), the unobserved early exercise premium (EEP) can be estimated by subtracting the observed theoretical European option price differential given on the right hand side (rhs) of (1) from the observed American option price differential, which leads to:

$$
\begin{gathered}
(C(t)-P(t))-(c(t)-p(t))=E E P_{C}-E E P_{P}=(C-P) \\
-\left(S e^{-r *(T-t)}-X e^{-r(T-t)}\right)
\end{gathered}
$$

where $C(t)$ and $P(t)$ are the time $t$ prices of American call and put options, respectively, and the $E E P$ are defined as: $C(t)=c(t)+E E P_{C}$ and $P(t)=p(t)+E E P_{P}$. Given that the rhs of (2) produces an observable estimate for the difference of $E E P$ 's, properties of the $E E P$ specific to currency options are used to enhance the estimate for the individual $E E P$ 's. In empirical estimation, the early exercise premium for the currency options are checked for consistency with the boundaries for the early exercise premium imposed by put-call parity.

The options data are divided into two subgroups with respect to "moneyness" defined as the ratio of the spot price to the exercise price $(S / X)$. In the money puts $(S<X)$ and in the money calls $(S>X)$ are used

5. Another use of put-call parities is to derive implicit prices, e.g., Lung and Nishikawa (2005) for currency options. 
to identify the two groups. Options that are near the money are not considered since the difference of the early exercise premiums for the options in this group can be attributed to both call and put options. More precisely, as the call (put) option goes deeper into the money, the $E E P_{P}$ $\left(E E P_{C}\right)$ for the paired put (call) option goes to zero because the probability of the option going deep enough into the money - a necessary condition for early exercise - gets small. In this case, the EEP difference in (2) is due only to $E E P_{C}\left(E E P_{P}\right){ }^{6}$ The exact definitions of moneyness for the paired groups used in section IV are as follows:

Group 1: In the money puts $S / X<0.99$

Group 2: In the money calls

$S / X>1.01$

These values are more restrictive than those in Poitras et al. (2007) where $S / X<0.995$ and $S / X>1.01$ are used to filter the sample of PHLX puts and calls respectively. The sharper boundaries result in a reduction in the number of available pairs from 529 to 372.

Following de Roon and Veld (1996), a multiple regression model is used to test the impact of four independent variables on the early exercise premium. The dependent variable used in the model is the relative early exericise premium $(R E E P)$. This is the early exercise premium expressed as a percentage of the option price. More precisely, REEP is calculated as the absolute value of $(A)$ minus $(B)$ divided by the in the money option price in which $(A)$ is the difference between the American call and put price and $(B)$ is the difference between the call and put price as implied by European put-call parity. The general regression equation being estimated is:

$$
R E E P=a+\beta_{1}\left(r-r^{*}\right)+\beta_{2}(T-t)+\beta_{3}(S / X)+\beta_{4}\left(\sigma_{\text {call }, t-1}\right)+\varepsilon
$$

The first independent variable to be considered involves the dependence of REEP on the difference between domestic and foreign interest rate levels. For calls, the REEP should increase as the difference between the foreign and domestic interest rates increases. This follows because the European lower boundary is $S e^{-r^{*}(T-t)}-X e^{-r(T-t)}$ which is lower than $S-X$ when $r^{*}>r$. In such cases, there is an incentive for the call to be

6. Applying (2) to get the $E E P_{P}$ results in a negative value when the put is deep in the money. Hence, when assessing $E E P_{P}$ either the absolute value of the estimate from (2) is used or, more directly:

$$
(P(t)-C(t))-(p(t)-c(t))=E E P_{P}-E E P_{C}=(P-C)-\left(X e^{-r(T-t)}-S e^{-r^{*}(T-t)}\right)
$$


exercised early which increases as the interest rate difference becomes larger. The situation for puts is the reverse: if the domestic rate is higher than the foreign rate, the REEP will be larger for the put. Comparison of the European lower bound with the intrinsic value leads to a second hypothesis that the early exercise premium increases with time to expiration. This holds for both calls and puts. However, this relationship is partially offset by the influence of time to expiration on the time value. As time to expiration increases, the probability that the option will be sold rather than exercised also increases.

Following Poitras et al. (2007), it is expected that the REEP for calls will increase as the third independent variable - the ratio of the spot price to the exercise price $(S / X)$ - increases. However, this relationship is not monotonic. On the one hand, when the spot price is higher than the exercise price, calls are in the money and thus, are more likely to be exercised. On the other hand, if the option gets very deep in the money, the theoretical trading value of the call reduces to $S e^{-r^{*}(T-t)}$ $-X e^{-r(T-t)}$, which is lower than the intrinsic value of $S-X$. In such a case early exercise will be optimal for the option holder and such options with be exercised and not be captured in the data set. The effect for puts is the opposite sign for calls. The early exercise premium is expected to decrease in absolute terms as the ratio of the spot price to exercise price increases because puts are moving in the direction of out of the money. For the fourth independent variable it is expected that the REEP increases as the exchange rate volatility increases. This hypothesis is not obvious. Jorion and Stoughton (1989) argue that a greater volatility raises the optimal exercise boundary for all maturities. However, it also increases the dispersion of future spot prices which makes it more likely that this boundary is struck before the option's maturity. According to Jorion and Stoughton (1989) the net effect is that increases in volatility also increase the value of the early exercise premium. The volatility is estimated as the implied volatility of the call option with the same exercise price and time to expiration on the day prior to the observation date $\left(\sigma_{\text {call }, t-1}\right)$. $^{7}$

\section{Data and Empirical Results}

Closing prices for currency options traded on the Philadelphia Stock

7. Notice that the implied volatility of call options is used for the put regressions. The reason for this is that the implied volatility of a call option gives a better estimate of the future volatility than the implied volatility of a put option. 
Exchange (PHLX) are examined for the period from January 2, 1992 to September 24, 1997. Over this period, the currency options on the PHLX experienced active trading and high volumes. The data covers the six currencies that were most actively traded, i.e. the Australian Dollar, the British Pound, the Canadian Dollar, the Deutsche (German) Mark, the Japanese Yen, and the Swiss Franc. Data on the exercise price, expiration date, spot exchange rate, and the closing prices of the options are derived from the PHLX database. The original database consists of 2,389 pairs of American call and put options that have the same trade date, underlying value, and exercise price. The data sorting process eliminates the options that are at the money $(1,233)$, because in this case it is most difficult to attribute the EEP solely to either puts or calls. From the 1,156 options that are left, options with prices that are not consistent with the boundaries of the American put-call parity are eliminated (325). Following Dueker and Miller (2003), 459 observations are eliminated, because they have a negative $E E P$ which is likely caused by non-synchronous reporting of the options and the spot prices. The remaining sample consisting of 372 observations is further filtered by removing 41 outlying observations where the REEP was greater than $15 \%$. The final sample of 331 put-call pairs is composed of 186 with in the money puts and 145 with in the money calls. Three-month Eurodollar interest rates, obtained from the US Federal Reserve Board website, are used for the domestic interest rate. ${ }^{8}$ These Eurodollar interest rates are applied to the covered interest rate parity condition to determine the foreign interest rates. For this purpose the currency futures traded on the International Money Market Division of the Chicago Mercantile Exchange are used. These futures have the same expiration cycle as the options traded on the PHLX. The futures prices are from the Thomson Financial Datastream database.

Table 1 summarizes the valuation of early exercise premium in the two groups. The table shows average premiums as a percentage of the average call or put price. In table 1, the average early exercise premium as a percentage of the put price is $5.03 \%$. The Japanese yen puts show the largest average early exercise premium compared to the puts on the other currencies, as expected for a country with the largest positive interest rate differential. The average early exercise premium as a percentage of the call prices is $4.60 \%$. As expected, the largest early

8. It is well known that Eurodollar interest rates are more appropriate then T-Bill rates in evaluation covered interest relationships, e.g., El-Mekkaoui and Flood (1998). Due to factors such as regulation and market structure the domestic T-Bill markets is less appropriate for capturing actual trade finance costs than the Eurodollar markets 
TABLE 1. Market Valuation of Early Exercise Premium

\begin{tabular}{|c|c|c|c|c|c|}
\hline & $\begin{array}{l}\text { No. of } \\
\text { observations }\end{array}$ & $\begin{array}{l}\text { Average US } \\
\text { minus foreign } \\
\text { interest rate, } \\
\%\end{array}$ & $\begin{array}{l}\text { Average } \\
\text { premium as } \\
\% \text { of option } \\
\text { price }\end{array}$ & $\begin{array}{l}\text { Median } \\
\text { premium as } \\
\% \text { of option } \\
\text { price }\end{array}$ & $\begin{array}{l}\text { Standard } \\
\text { deviation of } \\
\text { premiums } \\
(\%)\end{array}$ \\
\hline \multicolumn{6}{|l|}{ Group 1: Puts } \\
\hline$\overline{\text { Overall }}$ & 186 & 1.78 & $5.03 \%$ & 3.74 & 4.02 \\
\hline Aus. Dollar & 9 & -1.79 & $5.27 \%$ & 4.04 & 4.85 \\
\hline British Pound & 25 & -1.94 & $2.78 \%$ & 1.74 & 3.42 \\
\hline Can. Dollar & 19 & -0.99 & $3.92 \%$ & 2.41 & 3.54 \\
\hline Deutsche Mark & 36 & 1.94 & $4.59 \%$ & 3.90 & 3.20 \\
\hline Japanese Yen & 65 & 4.11 & $6.37 \%$ & 4.89 & 4.53 \\
\hline Swiss Franc & 32 & 2.43 & $5.01 \%$ & 4.53 & 3.33 \\
\hline \multicolumn{6}{|l|}{ Group 2: Calls } \\
\hline Overall & 145 & -1.02 & $4.60 \%$ & 3.15 & 3.99 \\
\hline Aus. Dollar & 19 & -1.56 & $6.12 \%$ & 5.43 & 3.83 \\
\hline British Pound & 39 & -2.78 & $5.12 \%$ & 4.03 & 3.65 \\
\hline Can. Dollar & 7 & -2.49 & $7.57 \%$ & 6.23 & 5.62 \\
\hline Deutsche Mark & 35 & -1.35 & $4.24 \%$ & 2.66 & 3.99 \\
\hline Japanese Yen & 19 & 1.38 & $4.04 \%$ & 1.90 & 4.43 \\
\hline Swiss Franc & 26 & 1.10 & $2.78 \%$ & 2.06 & 2.93 \\
\hline
\end{tabular}

Note: This table includes the relative early exercise premium of put and call options traded on the Philadelphia Stock Exchange between January 2, 1992 and September 24, 1997. This premium is calculated as the absolute value of (A) minus (B) divided by the in the money option price in which (A) is the difference between pairs of American call and put prices with the same $X$ and $T$ and (B) is the difference between the call and put price as implied by European put-call parity (see equations 1 and 2). In total 331 pairs of options are used. Puts are taken into account if the ratio of spot exchange rate $(S)$ and exercise price $(X), S / X<0.99$. Calls are taken into account if $S / X>1.01$.

exercise premium occurs for the countries with a negative interest rate differential. The overall results in table 1 are somewhat different from the results of Poitras et al. (2007) where the reported premiums of $5.71 \%$ for puts and $6.88 \%$ for calls are significantly larger. Given that Poitras et al. (2007) has the same sample except that a narrower range $(0.995<S / X<1.005)$ is used for defining at the money and the 41 outliers are included, the results for the $(0.99<S / X<1.01)$ with the outliers included are $5.89 \%$ for puts and $7.76 \%$ for calls. The largest outlier premiums are for the Deutsche Mark in both groups, likely caused by the large fluctuations in German interest rates in 1992-1993. The large fluctuations also explain why the average difference between the US and the German interest rate is positive for put options and 
negative for call options. In general, the differences within each group between the early exercise premiums for the different currencies can be substantial. For example, in Group 1 (puts) the early exercise premium for the Japanese Yen is $6.37 \%$ while the premium for the British Pound is only $2.78 \%$. In Group 2 (calls), the premium for the Canadian dollar is $7.57 \%$, while it is only $2.78 \%$ for the Swiss Franc. These large differences are consistent with there being significant cross-sectional variation in foreign interest rates.

Table 2 includes descriptive statistics for the dependent and independent regression variables for the 331 put and call option pairs in the sample. Examining the descriptive statistics reveals that the time to expiration of the options in the sample varies between five days and a little more than a year. The ratio of spot price to exercise price shows that most options are not very far in the money or out of the money, since the ratio never exceeds 1.121 for call options and is never below 0.910 for put options. The mean values of 0.98 for puts and 1.03 for calls are close to the in the money boundaries of 0.99 and 1.01 used to define the sample. This is consistent with the theoretical result from section II that very deep in the money options will be exercised and not sold because market makers will not quote prices above intrinsic value. The maximum EEP values of $14.62 \%$ for calls and $14.84 \%$ for puts can be compared to the maximum values for the sample with outliers included of $22.00 \%$ for puts and $34.09 \%$ for calls (Poitras et al. 2007).

Table 3 reports results for the regression of the relative early exercise premium $(R E E P)$ on the four independent variables. The coefficients for the interest rate differential confirm that the REEP is positively related to the difference between the domestic (US) and the foreign interest rate for puts and negatively for calls. The relevant coefficients in the put and call regressions are both significant at the 1\%-level. The results for time to expiration also both give the hypothesized sign, with the coefficient in the call regression being significant at the $1 \%$-level and the coefficient in the put regression having a $p$-value of $7.84 \%$. While insignificant, the results for moneyness do not give the hypothesized sign: the relationship between $R E E P$ and $S / K$ is positive for puts and negative for calls when the opposite signs are expected. This result is much different from Zivney (1991) who finds that the coefficient of the moneyness has the correct sign and highly significant. This is likely caused by differences between index options and currency options. Finally, the coefficients for volatility in both the put and call regressions are positive, as expected, though neither is statistically significant. In this context, the empirical results of Jorion and Stoughton (1989) report a negative, albeit 


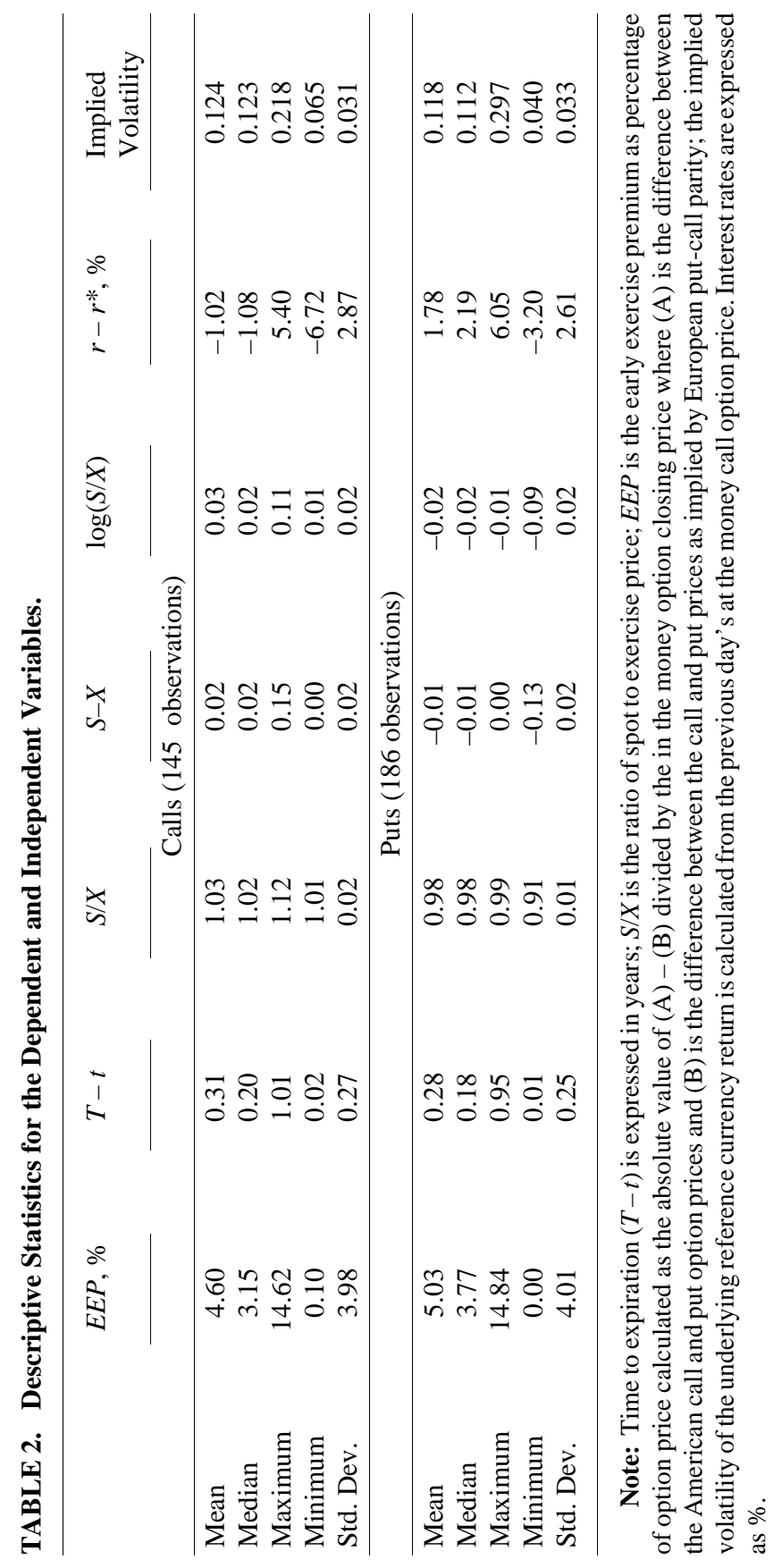


TABLE 3. Regression Results

\begin{tabular}{|c|c|c|c|c|c|c|}
\hline & Constant & $r-r^{*}$ & $T-t$ & $S / X$ & $\sigma_{\text {call }, t-1}$ & $\mathrm{R}^{2}$ \\
\hline \multicolumn{7}{|l|}{ Group 1: Puts } \\
\hline$\#$ obs. $=186$ & & & & & & \\
\hline $\begin{array}{l}\text { Coefficients } \\
\text { t-statistics }\end{array}$ & $\begin{array}{l}-0.25 \\
(-1.18)\end{array}$ & $\begin{array}{l}0.48 \\
(3.51 * *)\end{array}$ & $\begin{array}{c}0.02 \\
(1.77)\end{array}$ & $\begin{array}{c}0.28 \\
(1.34)\end{array}$ & $\begin{array}{l}0.095 \\
(0.96)\end{array}$ & 0.161 \\
\hline $\begin{array}{l}\text { Standard Error } \\
\text { of Regression }\end{array}$ & 0.037 & $\begin{array}{c}\text { Log } \\
\text { Likelihood }\end{array}$ & 340.27 & $\begin{array}{c}\text { F } \\
\text { statistic }\end{array}$ & 8.45 & \\
\hline \multicolumn{7}{|l|}{ Group 2: Calls } \\
\hline $\begin{array}{l}\# \text { obs. }=145 \\
\text { Coefficients } \\
\text { t-statistics }\end{array}$ & $\begin{array}{c}0.23 \\
(1.64)\end{array}$ & $\begin{array}{l}-0.54 \\
\left(-5.15^{* *}\right)\end{array}$ & $\begin{array}{l}0.05 \\
(3.61 * *)\end{array}$ & $\begin{array}{l}-0.21 \\
(-1.48)\end{array}$ & $\begin{array}{r}0.087 \\
(0.85)\end{array}$ & 0.293 \\
\hline $\begin{array}{l}\text { Standard Error } \\
\text { of Regression }\end{array}$ & 0.034 & $\begin{array}{c}\text { Log } \\
\text { Likelihood }\end{array}$ & 287.21 & $\underset{\text { statistic }}{\mathrm{F}}$ & 14.51 & \\
\hline
\end{tabular}

Note: The premium REEP is calculated as the absolute value of $(\mathrm{A})$ - (B) divided by the in the money option price in which (A) is the difference between the American call and put prices and (B) is the difference between the call and put prices as implied by the put-call parity. In total 331 pairs of call and put options with an identical exercise price and time to expiration are used. $T-t$ is the remaining time to expiration of the option in years; $r$ is the domestic (US) risk-free interest rate, and $r *$ is the foreign risk-free interest rate. In the money puts are used if the ratio of spot price $(S)$ and exercise price $(X), S / X<0.99$. Calls are taken into account if $S / X>1.010{ }^{*}=$ significant at the $5 \%$ level; $* *=$ significant at the $1 \%$ level. Values in brackets below coefficients are the $t$ statistics of the test that the coefficient value is equal to zero. Equations are estimated using Newey-West standard errors (lag truncation =4). $\quad R E E P=\alpha+\beta_{1}\left(r-r^{*}\right)+\beta_{2}(T-t)+\beta_{3}(S / X)+\beta_{4}\left(\sigma_{\text {call }, t-1}\right)+\varepsilon$

insignificant, relation between the early exercise premium for put options and volatility.

While most of the regression results in table 3 are consistent with theoretical predictions from section III, some are not. This suggests that further specification searches are in order. To this end, table 4 reports results for two alternative specifications: a sample with outliers included and an estimated regression with the moneyness variable excluded. In addition, White's test for heteroskedasticity (without cross terms) was estimated for all regressions reported in tables 3 and 4 . In studies involving cross sections, White's test is relevant for assessing the validity of a regression specification. In particular, the regression estimates using the sample with outliers included reported in table 4A appear to provide much stronger evidence about the determinants of the EEP. The overall regression fit is much higher than the comparable table 3 regression, the coefficient on time to expiration is highly 
TABLE 4. Regression Specification Assessment

A. Alternative Sample Specification (Outliers Included)

\begin{tabular}{|c|c|c|c|c|c|}
\hline Constant & $r-r^{*}$ & $T-t$ & $S / X$ & $\sigma_{\text {call, } t-1}$ & $\mathrm{R}^{2}$ \\
\hline $\begin{array}{c}0.17 \\
(0.68)\end{array}$ & $\begin{array}{l}0.66 \\
(4.12 * *)\end{array}$ & $\begin{array}{c}0.055 \\
\left(3.60^{* *}\right)\end{array}$ & $\begin{array}{l}-0.155 \\
(-0.62)\end{array}$ & $\begin{array}{c}0.064 \\
(0.51)\end{array}$ & 0.302 \\
\hline 0.044 & $\begin{array}{c}\text { Log } \\
\text { Likelihood }\end{array}$ & 333.42 & $\underset{\text { statistic }}{\mathrm{F}}$ & 20.46 & \\
\hline $\begin{array}{l}0.46 \\
(2.07 *)\end{array}$ & $\begin{array}{l}-1.10 \\
(-7.27 * *)\end{array}$ & $\begin{array}{l}0.12 \\
\left(6.13^{* *}\right)\end{array}$ & $\begin{array}{c}-0.50 \\
(-2.25 *)\end{array}$ & $\begin{array}{c}0.567 \\
\left(4.10^{* *}\right)\end{array}$ & 0.579 \\
\hline 0.053 & $\begin{array}{c}\text { Log } \\
\text { Likelihood }\end{array}$ & 269.13 & $\begin{array}{c}\mathrm{F} \\
\text { statistic }\end{array}$ & 58.75 & \\
\hline
\end{tabular}

Group 1: Puts

\# obs. $=195$

Coefficients

t-statistics

0.17

0.66

$0.055-0.155$

0.064

Standard Error

of Regression

$\log$

58.75

Group 2: Calls

\# obs. $=177$

Coefficients

t-statistics

kelihood

B. Alternative regression specification (Outliers Excluded)

\begin{tabular}{|c|c|c|c|c|c|}
\hline Constant & $r-r^{*}$ & $T-t$ & $S / X$ & $\sigma_{\text {call, } t-1}$ & $\mathrm{R}^{2}$ \\
\hline $\begin{array}{c}0.035 \\
\left(3.33^{* *}\right)\end{array}$ & $\begin{array}{c}0.496 \\
\left(3.66^{* *}\right)\end{array}$ & $\begin{array}{c}0.02 \\
(1.84)\end{array}$ & & $\begin{array}{r}0.020 \\
(0.25)\end{array}$ & 0.154 \\
\hline 0.037 & $\begin{array}{c}\text { Log } \\
\text { Likelihood }\end{array}$ & 339.53 & $\underset{\text { statistic }}{\mathrm{F}}$ & 10.76 & \\
\hline $\begin{array}{c}0.02 \\
(1.79)\end{array}$ & $\begin{array}{c}-0.534 \\
(-5.21 * *)\end{array}$ & $\begin{array}{l}0.05 \\
(3.47 * *)\end{array}$ & & $\begin{array}{c}0.037 \\
(0.40)\end{array}$ & 0.284 \\
\hline 0.034 & $\begin{array}{l}\text { Log } \\
\text { Likelihood }\end{array}$ & 286.25 & $\begin{array}{c}\mathrm{F} \\
\text { statistic }\end{array}$ & 18.61 & \\
\hline
\end{tabular}

Group 1: Puts

\# obs. $=186$

Coefficients

t-statistics

Standard Error

of Regression

Group 2: Calls

\# obs. $=145$

Coefficients

t-statistics

Standard Error

of Regression

Note: See Notes to Table 3

significant and has the correct sign in both regressions. In addition, the sign of the $S / X$ coefficient in the put regression is now negative as predicted, albeit insignificantly. Though the $S / X$ coefficient in the call regression in table $4 \mathrm{~A}$ is now significantly different than predicted, the coefficient on volatility is positive as predicted and highly significant. These favorable results can be contrasted with the $\chi^{2}(8)$ values 
generated by White's heteroskedasticity test for the call and put regressions. For the table 3 regressions, these values are 16.38 and 19.75 while the $\chi^{2}(8)$ for the table 4 regressions are 29.35 and $36.61 .^{9}$ While all the $\chi^{2}(8)$ values reject the null of homoskedasticity, the table 3 regressions are decidedly closer to this null and favor the sample with outliers excluded.

Another result from the table 4A regressions is that the unexpected negative sign for the $S / X$ variable observed in the call regression in table 3 continues. In addition, the volatility variable is now highly significant in the call regression. In contrast, the put regression of table $4 \mathrm{~A}$ has the correct sign for both $S / X$ and volatility but both coefficients are insignificant. This suggests the functional form of the regression equation may be mis-specified. To address this point, table 4B also reports results for a regression with $S / X$ omitted. Comparing the estimated coefficients with those in table 3 reveals little change for the interest differential or time to maturity. Dropping the $S / X$ variable does improve the overall fit of the regression, as reflected in the discernable improvement in the $F$ statistic. Though still insignificant and correct sign, the coefficient on volatility is smaller in both of the table 4B regressions. Regression results (not reported) employing other variations of moneyness, $(S-X)$ and $\log (S / X)$, did not produce substantively different results than those reported in table 3 . As expected, results for White's test do not differ much from those for the table 3 regression reported previously.

\section{Conclusions}

This paper adapts the methodology of Zivney (1991) for estimating the early exercise premium of currency options. Using the put-call parity condition to proxy the difference in the price of European call and put options with the same exercise price and time to expiration, empirical estimates of early exercise premiums that average $5.03 \%$ for put options and $4.60 \%$ for call options are provided. These estimated premia are found to be lower than those obtained when the sample is not adequately filtered for outliers. Adapting the regression specification of de Roon and Veld (1996) to currency options, regression estimates indicate that early exercise premiums are strongly influenced by the interest rate differential and, to a lesser extent, the time to expiration.

9. The corresponding $F(8,136)$ and $F(8,176)$ values are 2.17 and 2.63 with the $F(8,167)$ and $F(8,185)$ values being 4.17 and 5.38 . The value of the squared interest differential coefficient was significant in both put regressions. 
While the estimated coefficient for implied volatility has the correct sign in both put and call regressions, it is insignificant in the put regressions and only significant in the call regression when outliers are admitted. The results for moneyness, proxied by $S / X$, are usually the wrong sign and insignificant. This suggests that further analysis of the impact of moneyness on the early exercise premium is needed.

Accepted by: Prof. R. Taffler, Guest Editor, March 2008 Prof. P. Theodossiou, Editor-in-Chief, March 2008

\section{References}

Bodurtha, J.N., and Courtadon, G.R. 1995. Probabilities and values of early exercise: spot and futures foreign currency options. Journal of Derivatives 3: 57-75.

Bollen, N., and Rasiel, E. 2003. The performance of alternative valuation models in the OTC currency options market. Journal of International Money and Finance 22: 33-64.

De Roon, F., and Veld, C. 1996. Put-call parities and the value of early exercise for put options on a performance index. Journal of Futures Markets 16: 71-80.

Dueker, M., and Miller, T. 2003. Directly Measuring the Early Exercise Premiums using American and European S\&P 500 Index Options. Journal of Futures Markets 23: 287-313.

El-Mekkaoui, M., and Flood, M. 1998. Put-call parity revisited: intradaily tests in the foreign currency options market. Journal of International Financial Markets, Institutions and Money 8: 357-376.

Engström, M., and Nordèn, L. 2000. The early exercise premium in American put option prices, Journal of Multinational Financial Management 10: 461-479.

Garman, M., and Kohlhagen, S. 1983. Foreign Currency Option Values. Journal of International Money and Finance 2: 231-237.

Jorion, P., and Stoughton, N. 1989. An empirical investigation of the early exercise premium of foreign currency options. Journal of Futures Markets 9: 365-375.

Laprise, S.; Fu, M.; Marcus, S.; Lim, A.; and Zhang, H. 2006. Pricing American-Style Derivatives with European Call Options. Management Science 52: 95-110.

Lung, P., and Nishikawa, T. 2005. The implied exchange rates derived from option premiums: A test of the currency option boundary. Review of Futures Markets 14: 167-198.

Poitras, G. 2002. Risk Management, speculation, and derivative securities, New York: Academic Press.

Poitras, G.; Veld, C.; and Zabolotnyuk, Y. 2007. Put-Call Parity and the Early Exercise Premium for Currency Options. Review of Futures Markets 16: 159-169.

Zivney, T.1991. The value of early exercise in option prices: an empirical investigation. Journal of Financial and Quantitative Analysis 26: 129-138. 